\title{
A Lumped, Resonant Switched Capacitor Converter
}

\author{
Nakul Narayanan K., L. Umanand \\ Deptartment of Electronic Systems Engineering \\ Indian Institute of Science, Bangalore \\ Bangalore, India \\ nakul@iisc.ac.in
}

\author{
Andrew Cross, Hassan Taghizadeh \\ School of Mechanical, Electrical and Manufacturing Engineering \\ Loughborough University \\ Loughborough, UK \\ A.Cross@lboro.ac.uk
}

\begin{abstract}
This paper considers the output short-circuit protection of a Series-Parallel (S-P), switched capacitor converter for interfacing high-power PV farms and/or MV DC micro-grids. A so-called active interrupter can be used to isolate the converter from the fault; however, the inductor associated with this interrupter can used as the resonant inductor for the circuit, offering potential savings in inductor size/weight/cost and losses. A number of alternative S-P topologies were devised, which were compared against the existing circuit. Results from a scaled hardware prototype are presented, which highlights a number of practical issues related to circuit parasitcs.
\end{abstract}

Keywords-Power Electronics, DC-DC converters, Power Electronics Applications in Power Systems and Utilities

\section{INTRODUCTION}

Resonant switched capacitor (SC) converters are being proposed for high-power renewable energy applications that require a high DC voltage-conversion ratio. For example, High Voltage DC networks for off-shore wind and step-up, DC-DC converters for MV grid-tied inverters that connect LV batteries or PV panels to MV DC networks [1]-[3].

SC converters have the advantage that they can easily achieve high voltage-conversion ratios with high efficiency and where the voltage stress is inherently shared across the individual cells within the converter. This is achieved without, large bulky inductors making them particularly suitable for space and/or weight critical applications, for example urban sub-stations and offshore platforms [4]. Importantly, with the addition of very small inductors - typically air-cored - the circuit operates with zero-current switching (ZCS) across the complete range of output load.

This paper describes work that has been carried out between Loughborough University in the UK and the Indian Institute of Science (IISc), Bangalore as part of the Joint UKIndia Clean Energy initiative (JUICE) [5]. The project has focused on the investigation of direct connection of PV to the MV AC grid or DC network. The requirement is for a $100 \mathrm{~kW}$, non-isolated, unidirectional DC-DC converter, which steps-up the voltage from $600 \mathrm{~V}$ to several $\mathrm{kV}$ - gains of around $5 \rightarrow 30$. This can be difficult to achieve in high-power high-voltage applications where voltage insulation and a lack of high frequency transformers are a constraint [6], which is why an $\mathrm{SC}$ converter is being considered here. This paper focusses on the protection of the SC converter against short-circuit-toground faults on the network side of the converter.

High-power converters that connect energy sources to power networks must achieve high availability. However, they are particularly vulnerable to indiscriminate short-circuit faults within the network to which they are connected. Shortcircuit faults are a particular issue for SC converters because (a) the overall stored energy in the cell capacitors can be significant, and (b) the SC converter has no inductor and so cannot operate in current-limit during external faults.
This paper describes a modification to a traditional SC resonant topology that uses the cell ZCS inductors to limit the rate-of-rise of short-circuit fault current. This then allows a blocking transistor to rapidly isolate the converter from the faulted network. Three new converter circuits are compared against the existing circuit and results from a 4-cell, lowpower, hardware prototype are presented.

There are numerous papers on the protection of SC converters primarily for use in low-power, on-chip applications such as over temperature, startup-shutdown and even cyber-attacks [7]. But nothing specifically about shortcircuits faults with high-power converters. Whilst there appears to be related work on the protection of the flying capacitor multilevel converter (FCMC) [8], the inductor and modulation control used in the flying capacitor circuit allow current-mode control. This is a critical difference between how faults are handled in the FCMC converter compared with the SC converter.

\section{FAult ANALysis FOR THE SERIES-PARALlEL SC CONVERTER AND SYNTHESIS OF THE LUMPED VERSION}

A SC converter can be realised as the interconnection of the so-called Canonical Cell shown in Fig. 1.

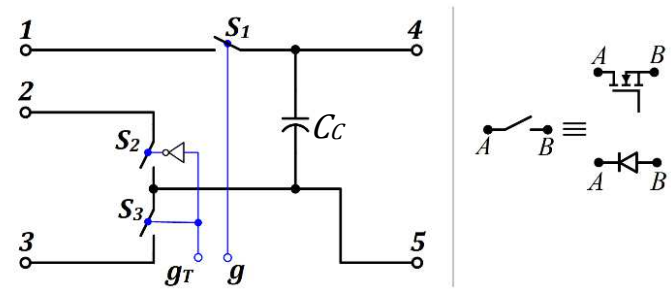

Fig. 1. Switched Capacitor Canonical Cell

The cell consists of three-switches $S_{1} \rightarrow S_{3}$, with gatedrive signals $g_{T}$ and $g$, and a cell capacitor $C_{C}$ [9]. For a resonant converter, which provides soft-switching, a small inductor is connected in series with the capacitor. This ensures the cell current is sinusoidal and synchronised to the gatesignal so that all three switches turn on/off at the zero crossing, resulting in ZCS. The switches can be implemented as either transistors or diodes depending on whether the converter is unidirectional or bi-directional. The gate signals are switched with a constant $50 \%$ duty-cycle, the two halves of the cycle corresponding to a cell capacitor charging cycle, followed by a discharge cycle.

The cells can be connected in numerous ways to form a variety of circuits. For protection purposes the Series-Parallel converter (S-P) is a good choice because the overall VoltAmpere rating of the capacitors is a minimum and hence stored energy is low, which helps reduce the level of shortcircuit fault currents.

A modified version of the traditional resonant SeriesParallel resonant converter, with input voltage $V_{i n}$ is shown as the N-cell circuit in Fig. 2. The cell capacitors and resonant 
inductors, which are denoted $C_{C}$ and $L_{C}$ respectively, have the same value for each cell.

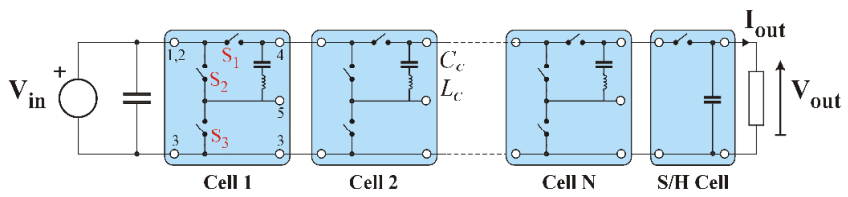

Fig. 2. Resonant Series-parallel SC converter where $S_{1}$ and $S_{2}$ are LV rated

The final cell shown in Fig. 2 is known as a sample andhold cell $(\mathrm{S} / \mathrm{H})$, which is used to capture the discharge cycle of the cells; this cell provides the converter DC output voltage and current $V_{\text {out }}$ and $I_{\text {out }}$ respectively.

The step-up ratio between the input and output voltage is given by $V_{\text {out }} / V_{\text {in }}=N+1$. The source will be inductive, especially if it is part of a DC, network, therefore an input decoupling capacitor is required to ensure the resonant frequency of each cell is unaffected by the supply impedance.

This variation of the traditional S-P topology is more suitable for high-voltage applications because cell switches $S_{1}$ and $S_{2}$ are only rated to the low-voltage input of the converter $V_{i n}$, whereas with the traditional converter only $S_{2}$ is LV rated. An important disadvantage with this circuit is that parasitic circuit resistance significantly affects the quality factor of the downstream cell resonant circuits. This limits the maximum number of cells and hence voltage gain $<10$.

Since the application considered here is for a unidirectional, step-up converter, this means switch $S_{1}$ can be implemented as a diode as shown in Fig. 3. For high power applications, the switches $S_{2}$ and $S_{3}$ are shown as IGBTs.

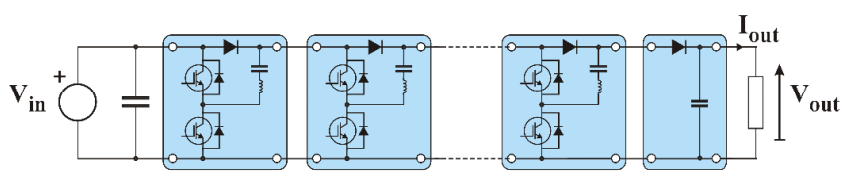

Fig. 3. High-power, unidirectional converter utilising diodes and IGBTs

If a short-circuit fault occurs on the network side of the converter - Fig. 4, the converter switches will be unable to block the fault. Therefore, the input source $V_{i n}$, input decoupling capacitor $C_{i n}$, cell capacitors and $\mathrm{S} / \mathrm{H}$ capacitor $C_{\text {out }}$ will all contribute to the fault.

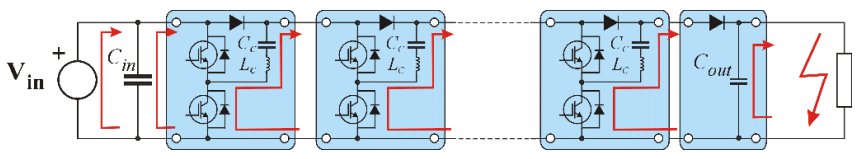

Fig. 4. Fault current paths during a network-side fault

The resonant inductor $L_{C}$, within each cell limits the magnitude of the resonant fault currents due to cell capacitors $C_{C}$, to a peak value of $V_{i n} / \sqrt{L_{C} / C_{C}}(\mathrm{~A})$. However, a rapid disconnection of the converter from the fault is needed to protect the converter against faults from the input supply $V_{i n}$, and the output $\mathrm{S} / \mathrm{H}$ capacitor $C_{\text {out }}$. This can be achieved using a so-called Active Current Interrupter shown in Fig. 5, which consists of an inductor, transistor and freewheel diode [3]. The inductor is used to limit the rate-of-rise of fault current so that the transistor can open in a few micro-seconds. The diode provides a free-wheel path for the inductor when the transistor opens. In this way, over-currents well within the capability of the convertor components can be accommodated.

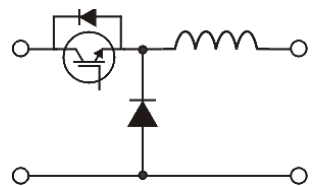

Fig. 5. Active Interrupter used as a high-speed electronic circuit breaker

The Active Interrupter can be placed either at the output or input of the converter as shown in Fig. 6(a) and (b) respectively - note: one of the cells in the previous figures has been removed for clarity. The circuit in Fig. 6(b), requires an additional capacitor between the interrupter and the first cell to isolate the interrupter inductor from the resonance occurring within the cells.

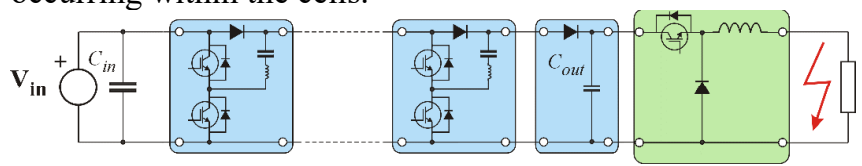

(a)

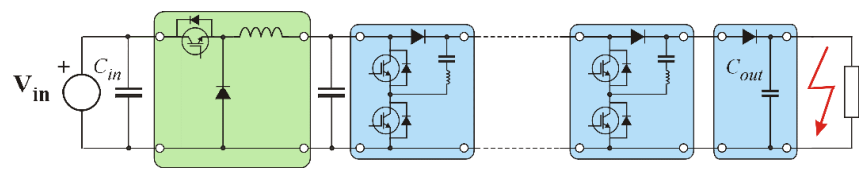

(b)

Fig. 6. Series-Parallel converter with interrupter at (a) output and (b) input

With the first topology Fig. 6(a), the interrupter protects all the switches and capacitors. However, the interrupter switch voltage rating must be at the high-voltage side of the converter. Such a switch, for example using series-connected transistors, is difficult to realise in practice.

The interrupter switch for the second converter Fig. 6 (b), is low-voltage, which can be easily implemented using a single high-current IGBT module. This is a very significant benefit compared to the first circuit. However, unlike the first topology, the interrupter only protects the capacitor $C_{\text {in }}$ and isolates the input source voltage from the fault. Fortunately, the cell capacitors themselves are protected from excessive peak currents by their own resonant inductors $L_{C}$, but this still leaves the additional decoupling capacitors and the $\mathrm{S} / \mathrm{H}$ capacitor unprotected. This latter point is considered below.

It is now proposed that under normal operation the function of the cell resonant inductors in Fig. 6 (b), can be subsumed by the interrupter inductor. The resonant inductors and additional decoupling capacitor can be removed from the circuit. Whilst an additional inductor is needed at the converter output to protect $C_{\text {out }}$, the overall benefits of only needing an LV interrupter switch and merging the cell inductors into one component are very desirable. The investigation of this converter, which has been termed a Lumped Series-Parallel (S-P) converter is described in the following sections of this paper. The circuit is shown Fig. 7, where the inductor $L_{\text {out }}$ has been added to protect the $\mathrm{S} / \mathrm{H}$ capacitor. The active interrupter inductor now takes on the additional function of a resonant inductor for the cell capacitors and is denoted $L_{i n}$.

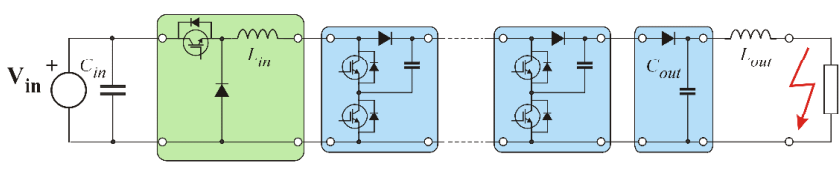

Fig. 7. Proposed Lumped Series-Parallel (S-P) converter circuit 


\section{LUMPED S-P CONVERTER VARIANTS}

An initial analysis of the new Lumped converter during normal operation assumes that the resonant period during capacitor charging is the same as that for the traditional S-P converter - the latter will herein be referred to as a Distributed converter.

\section{A. Traditional Distributed Converter}

All cells have the same value for the cell capacitor $C_{C}$ and also the inductor $L_{C}$, other than the sample and hold cell, which has $C_{\text {out }} \gg C_{C}$. The cell capacitor current waveform $i_{\mathrm{C}_{C}}$, over one switching period $T_{S}(\mathrm{~s})$, is the same for all $N$ cells and is shown in Fig. 8:

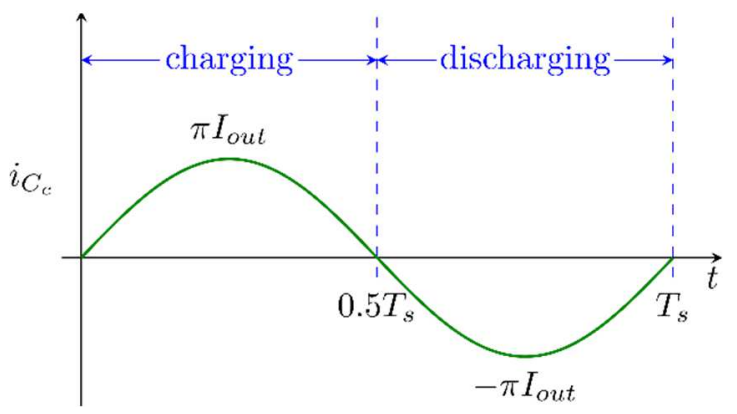

Fig. 8. Distributed converter cell capacitor current waveform.

By design, the resonant circuit should have a high-quality factor Q, such that the currents in the charge / discharge periods are sinusoidal. Expressions for the peak currents in terms of the converter output current $I_{\text {out }}$, can be obtained by considering the average power through a cell in terms of the converter output power. This analysis then gives amplitudes of $\pm \pi I_{\text {out }}$ as shown in Fig. 8 .

The cell resonant components are related to the switching period by,

$$
T_{S}=2 \pi \sqrt{L_{c} C_{c}}
$$

The capacitor $C_{c}$ is chosen based on a per-unit, peak-peak voltage ripple specification for the cell, denoted $r$, typically having a value equivalent to $5 \%$,

$$
C_{C}=\frac{I_{\text {out }} T_{S}}{r V_{\text {in }}}
$$

\section{B. Lumped Converter}

During charging, the converter must achieve the same resonant period as the Distributed converter (1). Since the lumped inductor $L_{\text {in }}$ now resonates with all the parallel connection of the cell capacitors, then,

$$
L_{\text {in }}=\frac{L_{c}}{N}
$$

During the subsequent discharge period, $L_{\text {in }}$ resonates with the series connection of the capacitors and hence unlike the distributed converter, the resonant period will be shorter than the charging period. This is shown by the cell capacitor current waveform in Fig. 9. The cell capacitor current waveform terminates early during the discharge period, such that the switching cycle has a period of zero-current. Generally, this mode of operation should be avoided as it leads to higher RMS current and peak current in the components. Two other variants of the circuit are therefore proposed for comparison. In the first case, the transistor duty-cycle and converter switching frequency are adjusted as shown in Fig.
10 , which shortens the switching cycle and avoids the period of zero current.

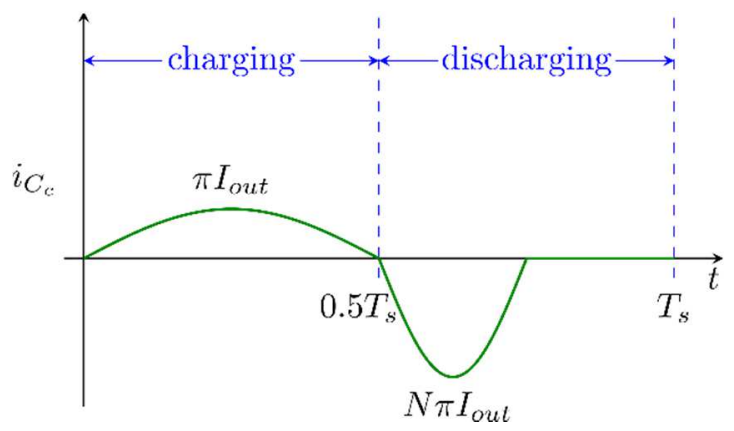

Fig. 9. Lumped converter current waveform for the input inductor $L_{i n}$.

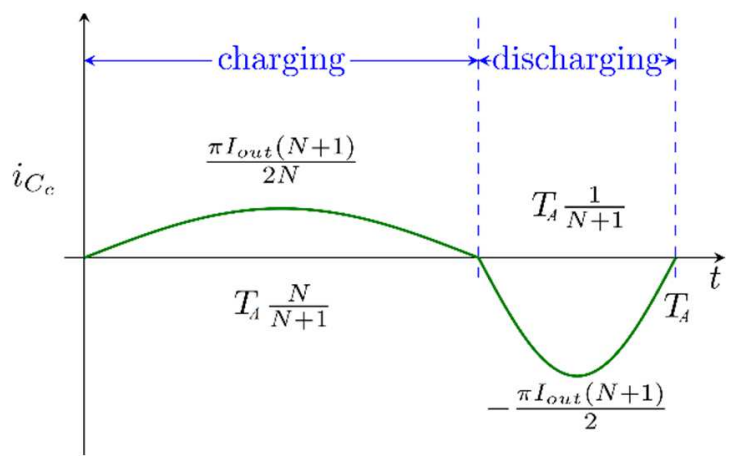

Fig. 10. Lumped converter $L_{\text {in }}$ current waveform, avoiding zero current

The new switching frequency period $T_{A}$, is given by $T_{A}=$ $(N+1) T_{S} / 2 N$. The duty-cycle $D$, which is defined as the duration of the charging period over the switching period $T_{A}$ is given by $D=N /(N+1)$. Since the converter maintains $\mathrm{ZCS}$, the only penalty in increasing the switching frequency is that the $\mathrm{AC}$ resistance of the wound components will be higher.

No increase in the switching frequency or duty-cycle is needed for the second circuit variant, but it does require the additional retuning inductor $L_{\text {res }}$ at the output of the $N^{\text {th }}$ cell as shown in Fig. 11,

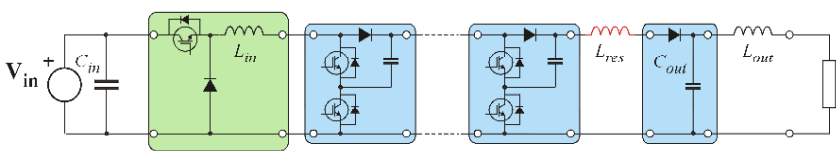

Fig. 11. Lumped converter $L_{\text {in }}$ current waveform, \& retuning inductor $L_{\text {res }}$

The function of $L_{r e s}$ is to retune the resonant frequency during the discharge period of the converter to remove the period of zero current, so that,

$$
L_{\text {res }}=\left(N^{2}-1\right) L_{\text {in }}
$$

The current waveform for the cell capacitors $i_{\mathrm{C}_{C}}$, is then identical to that of the Distributed converter shown in Fig. 8.

\section{COMPARISON OF S-P CONVERTER VARIANTS}

Before commencing it is worth summarising the four different converters that are to be compared, which are: (i) the traditional Distributed converter Fig. 6(a)/Fig. 8 and the Lumped converter and its variants, (ii) with $D=0.5$ dutycycle Fig. 9, (iii) with an asymmetric duty-cycle $D=$ $N /(N+1)$ Fig. 10 and (iv) with $D=0.5$ duty-cycle but having an additional re-tuning inductor $L_{\text {res }}$ Fig. 11/Fig. 8. 
The following comparison is made assuming the cell capacitors have the same value for the Distributed converter and its three variants. Note the voltage rating requirements for the capacitors and switches are identical for all the converters and are therefore ignored. Expressions for the average and RMS currents for the four converter variants have been obtained to compare switch, inductor and capacitor conduction losses. The switch average currents are identical for all four converters and equal to $i_{\text {out }}$ for $S_{2}$ and $S_{3}$, and $j \times$ $i_{\text {out }}$ for $S_{1}$, where $j=N \rightarrow 1$ as the cell number $1 \rightarrow N$. Equations for the RMS currents are shown in TABLE I.

TABLE I. NORMALISED RMS CURRENTS FOR THE SC VARIANTS

\begin{tabular}{|c|c|c|c|}
\hline \multirow{2}{*}{} & \multicolumn{3}{|c|}{ RMS currents normalised to $\boldsymbol{I}_{\text {out }} / \mathbf{2}$} \\
\cline { 2 - 4 } & $\begin{array}{c}\text { Distributed/ } \\
\text { retuned Lumped }\end{array}$ & $\begin{array}{c}\text { Lumped } \\
\boldsymbol{D}=\mathbf{0 . 5}\end{array}$ & $\begin{array}{c}\text { Lumped } \\
\boldsymbol{D}=\boldsymbol{N} /(\boldsymbol{N}+\mathbf{1})\end{array}$ \\
\hline $\boldsymbol{C}_{\text {in }}$ & $\sqrt{N^{2}+1-\frac{4}{\pi^{2}}(N+1)^{2}}$ & $\sqrt{N^{2}+N-\frac{4}{\pi^{2}}(N+1)^{2}}$ & $(N+1) \sqrt{\frac{1}{2}-\frac{4}{\pi^{2}}}$ \\
\hline $\boldsymbol{L}_{\text {in }}$ & $\begin{array}{c}\sqrt{N^{2}+1} \\
(\text { retuned only) }\end{array}$ & $\sqrt{N(N+1)}$ & $(N+1) / \sqrt{2}$ \\
\hline $\boldsymbol{C}_{\boldsymbol{C}}$ & $\sqrt{2}$ & $\sqrt{N+1}$ & $(N+1) / \sqrt{2 N}$ \\
\hline $\boldsymbol{j}^{\text {th }} \boldsymbol{C e l l}_{\boldsymbol{1}}$ & $j$ & $j$ & $j \sqrt{(N+1) / 2 N}$ \\
\hline $\boldsymbol{S}_{\mathbf{1}}$ & 1 & $\sqrt{N}$ & $\sqrt{(N+1) / 2}$ \\
\hline $\boldsymbol{S}_{\mathbf{3}}$ & 1 & 1 & $\sqrt{(N+1) / 2 N}$ \\
\hline $\boldsymbol{L}_{\text {res }}$ & 1 & - & - \\
\hline $\boldsymbol{S} / \boldsymbol{H} \boldsymbol{S}_{\mathbf{1}}$ & 1 & $\sqrt{N}$ & $\sqrt{(N+1) / 2}$ \\
\hline $\boldsymbol{S} / \boldsymbol{H} \boldsymbol{C}_{\text {out }}$ & $\sqrt{1-4 / \pi^{2}}$ & $\sqrt{N-4 / \pi^{2}}$ & $\sqrt{\left(\frac{N+1}{2}\right)-\frac{4}{\pi^{2}}}$ \\
\hline $\boldsymbol{L}_{\text {out }}$ & $2 / \pi$ & $2 / \pi$ & $2 / \pi$ \\
\hline
\end{tabular}

Another metric for comparison purposes is the ripple voltage on the capacitors. Expressions have been derived for each converter and are shown in TABLE II. The value of the input capacitor $C_{i n}$, is determined by grid decoupling requirements and its value will be the same for all the converters. It is therefore not included in TABLE II.

TABLE II. NORMALISED CAPACITOR RIPPLE FOR THE SC VARIANTS

\begin{tabular}{|c|c|c|c|}
\hline \multirow{2}{*}{$\begin{array}{c}\text { For } \\
\text { capacitor: }\end{array}$} & \multicolumn{3}{|c|}{ Capacitor ripple voltage normalised to $\boldsymbol{I}_{\text {out }} \boldsymbol{T}_{\boldsymbol{S}}$} \\
\cline { 2 - 4 } & $\begin{array}{c}\text { Distributed } \boldsymbol{\&} \\
\text { Retuned Lumped }\end{array}$ & $\begin{array}{c}\text { Lumped } \\
\mathbf{D}=\mathbf{0 . 5}\end{array}$ & $\begin{array}{c}\text { Lumped } \\
\boldsymbol{D}=\boldsymbol{N} /(\boldsymbol{N}+\mathbf{1})\end{array}$ \\
\hline \multirow{2}{*}{$\boldsymbol{C}_{\boldsymbol{C}}$} & $1 / C_{C}$ & $1 / C_{C}$ & $(N+1) / 2 N C_{C}$ \\
\hline $\boldsymbol{C}_{\text {out }}$ & $\frac{1}{k C_{\text {out }}}\left(\frac{\sin ^{-1}\left(\frac{1}{k \pi}\right)}{\pi}-\frac{1}{2}+\sqrt{k^{2}-\frac{1}{\pi^{2}}}\right)$ \\
\cline { 2 - 4 } & $k=1$ & $k=(N+1) / 2$ \\
\hline Note: & $T_{S}=$ switching period of the Distributed converter \\
\hline
\end{tabular}

The first initial observation from these two tables is that since the switch and inductor components for the two Lumped converters: $D=0.5$ and $D=N /(N+1)$, are the same, then because the RMS current terms in TABLE I, and the capacitor voltage ripple, TABLE II, are greater for the $D=0.5$ case, this circuit can be disregarded from further consideration.

The requirements for the inductive components are used as a final means of comparison. To simplify this appraisal, it is assumed from (3) that $L_{i n}$ for the Lumped converter, is fabricated from $N \times$ cell inductors $L_{C}$, connected in parallel. This means the cost - including size/weight - is the same for both the Distributed and Lumped converters. However, in practice there will be advantages/disadvantages in constructing $L_{\text {in }}$ as a single component, for example less copper, but a reduced surface area for cooling. A discussion of inductor requirements now follows:

\section{A. Resonant inductors $L_{C}, L_{i n}$ and $L_{\text {res }}$}

As stated above, the size/weight of the $N$ cell inductors for the Distributed converter and $L_{\text {in }}$ for the Lumped converter are the same. Therefore, only a comparison of conduction losses is needed using the $2^{\text {nd }}$ and $3^{\text {rd }}$ rows of TABLE I.

The Retuned Lumped converter also has the additional resonant inductor $L_{r e s}$. Using (5) and making the simplifying assumption that $N^{2}-1 \approx N^{2}$, then $L_{\text {res }}$ can be referred to the input side of the converter as $L_{i n}$. The Retuned converter therefore appears to have an input inductor $2 L_{i n}$.

The inductor conduction losses for $L_{C}, L_{i n}$ and $L_{\text {res }}$ as a function of the number of cells $N$, are shown in TABLE III.

TABLE III. TOTAL RESONANT INDUCTOR CONDUCTION LOSS NORMALISED TO THE DISTRIBUTED CONVERTER, FOR N $=2 \rightarrow \infty$

\begin{tabular}{|c|c|c|c|}
\hline & Distributed & $\begin{array}{c}\text { Lumped } \\
\boldsymbol{D}=\boldsymbol{N} /(\boldsymbol{N}+\mathbf{1})\end{array}$ & Retuned Lumped \\
\hline $\begin{array}{c}\text { Inductor cond. } \\
\text { loss, } \boldsymbol{L}_{\boldsymbol{C}} \& \boldsymbol{L}_{\text {in }}\end{array}$ & 1 & $\frac{9}{16} \rightarrow \frac{1}{4}$ & $\begin{array}{c}1 \\
\left.\text { (Includes } \boldsymbol{L}_{\text {res }}\right)\end{array}$ \\
\hline
\end{tabular}

From (5), for large values of $N$, inductor $L_{r e s}$ will have a relatively high value of inductance and therefore require a ferro-magnetic core. In which case, core-losses should also be factored into the entry for the Retuned Lumped converter in TABLE III. Assuming core and conduction losses are equal, this would effectively raise the table entry from 1 to 1.5.

\section{B. Output inductor $L_{\text {out }}$, and switch interupptor inductance}

These two inductors are used solely for protection. The Distributed converter only has an interrupter inductor Fig. 6 (a), and inductor $L_{\text {out }}$ is not required, whereas, the opposite is true for the Lumped circuits where the role of the interrupter inductor is subsumed by $L_{i n}$. Note, the retuning inductor $L_{r e s}$ also appears to assist these two inductors in terms of protection. However, since it is fabricated on a ferromagnetic core it would saturate under short-circuit conditions and can be ignored.

The appraisal therefore reduces to a comparison between the interrupter inductor for the Distributed converter - here termed $L_{\text {int }}$ - and $L_{\text {out }}$ for the Lumped converter. During normal operation, both inductors conduct the same current $i_{\text {out }}$ so this mode is not relevant. Under faulted conditions, the output short-circuit current waveform will initially be dominated by the discharge of the output capacitor $C_{\text {out }}$ since the upstream cell capacitors and $V_{\text {in }}$ are initially blocked by the $S_{1}$ diode. This discharge current will be sinusoidal through either the interrupter inductor $L_{\text {int }}$ for the Distributed converter, or $L_{\text {out }}$ for the Lumped converter. The peak fault current for the Lumped converter will then be 
$V_{\text {out }} / \sqrt{L_{\text {out }} / C_{\text {out }}}$. For the Distributed converter, the peak fault current will be the over-current trip level set for the interrupter:

$$
\text { overcurrent trip level }=\frac{V_{\text {out }}}{\sqrt{L_{\text {int }} / C_{\text {out }}}} \sin \left(\frac{T_{S C}}{\sqrt{L_{\text {int }} C_{\text {out }}}}\right)
$$

where $T_{S C}$ is the trip time of the interrupter, having a typical value for IGBTs of $10 \mu \mathrm{s}$. The ratio of the peak fault currents for the two converters termed $m$, is then,

$$
m=\sqrt{\frac{L_{\text {int }}}{L_{\text {out }}}} \frac{1}{\sin \left(\frac{T_{S C}}{\sqrt{L_{\text {int }} C_{\text {out }}}}\right)}
$$

Capacitors have a higher surge current rating than IGBTs, so that typically $m$ has a value of at least 10 . Re-arranging (7) as an implicit equation in terms of $L_{\text {int }}$,

$$
L_{\text {int }}=\frac{1}{C_{\text {out }}}\left(\frac{1}{T_{S C} \sin ^{-1}\left(\sqrt{\frac{L_{\text {int }}}{L_{\text {out }}}} / m\right)}\right)^{2}
$$

Typical values for the output capacitor for an SC converter with a switching frequency of $10 \mathrm{kHz}$ are $C_{\text {out }}=1 \rightarrow 10 \mu \mathrm{F}$. Therefore, in order to get practical values for $L_{\text {int }}$ from equation (8), which would typically be in the range of $10 \mathrm{~s}$ of $\mu \mathrm{H}$ for an air-core inductor, the equation shows the term $L_{\text {int }} / L_{\text {out }}$ in the denominator gives $L_{\text {int }}>50 L_{\text {out }}$. The inductor $L_{\text {out }}$ therefore adds no significant additional cost to the Lumped converter when compared with $L_{i n t}$ for the Distributed converter.

A summary of the comparison of conduction losses and inductive requirements against the Distributed circuit are

\begin{tabular}{|c|c|c|}
\hline \multirow[b]{2}{*}{ Criterion } & \multicolumn{2}{|c|}{ Converter } \\
\hline & Lumped $D=N /(N+1)$ & Retuned Lumped \\
\hline Cond. loss : $L_{\text {in }}$ & $\approx 45-50 \%$ less & No change \\
\hline $\begin{array}{c}\text { Cond. loss: } S_{1} \\
\& \& S_{3}\end{array}$ & $\approx 25-50 \%$ less & " \\
\hline Cond. loss : $S_{2}$ & $\begin{array}{l}\text { At least } 50 \% \text { higher, } \\
\text { increasing with } \mathrm{N}\end{array}$ & “ \\
\hline Cond. loss : $C_{\text {in }}$ & $\approx 37-85 \%$ less & " \\
\hline Cond. loss : $C_{C}$ & $\begin{array}{l}\text { At least } 10 \% \text { higher, } \\
\text { increasing with } \mathrm{N}\end{array}$ & " \\
\hline $\begin{array}{c}\text { Cond. loss : } \\
C_{\text {out }}\end{array}$ & $\begin{array}{l}\text { At least } 85 \% \text { higher, } \\
\text { increasing with } \mathrm{N}\end{array}$ & " \\
\hline $\begin{array}{c}\text { Cond. loss : } \\
L_{\text {int }} \\
\end{array}$ & $\begin{array}{c}\mathrm{N} / \mathrm{A} \\
\text { (part of } \boldsymbol{L}_{\boldsymbol{i n}} \text { above) }\end{array}$ & “ \\
\hline $\begin{array}{l}\text { Additonal } \\
\text { inductors }\end{array}$ & $L_{\text {out }}:$ no significant cost & $\begin{array}{c}L_{\text {res }}: \text { costly } \\
L_{\text {out }}: \text { no significant } \\
\text { cost }\end{array}$ \\
\hline $\begin{array}{l}\text { Interruptor } \\
\text { switch }\end{array}$ & $\begin{array}{l}\text { High-current, low-voltage } \\
\text { rated }\end{array}$ & $\begin{array}{l}\text { High-current, low- } \\
\text { voltage rated }\end{array}$ \\
\hline
\end{tabular}
shown in TABLE IV.

TABLE IV. SUMMARY OF CONVERTER REQUIREMENTS, FOR N=2 $\rightarrow \infty$

From TABLE IV the Retuned Lumped converter has almost the same performance as the Distributed circuit, other than it has the disadvantage of needing the additional inductor $L_{\text {res }}$. On the other hand, it has the significant advantage that the interrupter switch is rated at the LV side of the converter.
Likewise, the Lumped converter with asymmetric dutycycle $D=N /(N+1)$, has the advantage of requiring a lowvoltage interrupter switch. In addition, unlike the Lumped Retuned converter it does not require the inductor $L_{r e s}$. More importantly, the conduction losses in the more lossy components - inductors and switches - are lower than both the other two converters. However, this is not the case for IGBT $S_{3}$, where losses are higher. Whilst the losses in the cell and output capacitors are also higher, these components generally have much lower equivalent series resistance. Therefore, the Lumped converter with asymmetric converter may be a good candidate for low values of $N$, and for higher values of $N$ if the overall losses in IGBT $S_{3}$ are offset by the savings in the other two switches and inductors.

\section{HARDWARE PROTOTYPE AND RESUltS}

Scaled-hardware prototypes of the Distributed, Lumped asymmetric duty-cycle and Lumped Retuned converters were built and tested in the laboratory. The converter had three cells and a $\mathrm{S} / \mathrm{H}$ cell giving a voltage gain of four. The nominal input/output voltage was $30 \mathrm{~V}: 120 \mathrm{~V}$ and the output power $100 \mathrm{~W}$. Each cell consisted of two Infineon IRF100P218, $100 \mathrm{~V}, 218 \mathrm{~A}$, MOSFETs for $S_{2}$ and $S_{3}$, and a Wolfspeed CVFD20065A, $200 \mathrm{~V}, 65$ A silicon carbide schottky diode for $S_{1}$. The cell-capacitors were $22 \mu \mathrm{F}$ polypropylene giving a cell-ripple of $5 \%$ for a nominal switching frequency of $10 \mathrm{kHz}$. The $\mathrm{S} / \mathrm{H}$ cell capacitor $C_{\text {out }}$ was selected as $470 \mu \mathrm{F}$, and the converter input capacitor $22 \mathrm{uF}$. However, the bench DC supply used to emulate $V_{\text {in }}$ had a poor high frequency response and required additional $4 \mathrm{mF}$ decoupling at its output terminals. The global clock signal, which included a deadtime of $80 \mathrm{~ns}$ between $S_{2}$ and $S_{3}$, was generated by an offboard DSP.

\section{A. Distributed SC converter}

Using (1), the cell inductor was chosen as $10 \mu \mathrm{H}$. Measured waveforms of the cell 1, $S_{3}$ gate signal (yellow), cell 1 input current (blue), and the converter DC input and output voltages $V_{\text {in }}$ (green) and $V_{\text {out }}$ (red), are shown in Fig. 12.

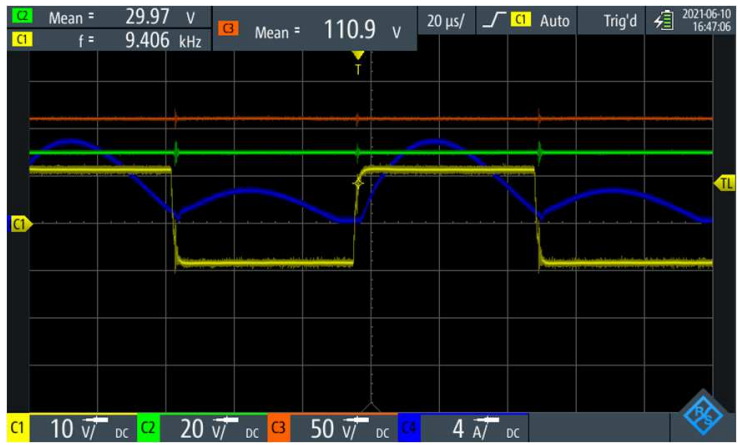

Fig. 12. Measured cell 1 input current (C4, blue, 2A/div), global gate signal (C1, yellow, 10V/div), $V_{\text {in }}$ (C2, green, 20V/div), $V_{\text {out }}(\mathrm{C} 3$, red, 50V/div); time axis: $20 \mu \mathrm{s} / \mathrm{div}$

It was initially found that circuit parasitics caused the resonant frequency to be lower than expected so that ZCS was not achieved. This was overcome by reducing the switching frequency to $9.4 \mathrm{kHz}$. The converter then operated as expected (Fig. 12), having a ripple-free output voltage and ZCS operation, the latter indicated by the current reaching zero as the gate voltage changes state. The step-up ratio was 3.7, which corresponds to a full-load voltage regulation of $7.5 \%$, which is typical for $\mathrm{S} / \mathrm{C}$ converters. 
Nevertheless, it can be seen from Fig. 12 that the shape of the current was not the expected ideal sinusoidal shape. This was due to excessive damping - low Q. Also, the resonant frequency during the discharge period did not match switching frequency. This was thought to be due to parasitic resistance and inductance. To confirm this, further measurements were used to calculate the parasitics using the non-linear curve fitting technique described in [10]. Subsequent circuit simulation which included these parasitics, then gave a close agreement with the measured current waveform of Fig. 12.

\section{B. Lumped SC}

Both the Lumped asymmetric duty-cycle and Retuned circuits were tested using the prototype by shorting the cell inductors of the Distributed converter. Equation (4) was used to calculate $L_{\text {in }}=3.3 \mu \mathrm{H}$. However, it was then found that with this reduced inductance the parasitics were more dominant, making ZCS in all cells difficult to achieve. For example, with the Retuned Lumped converter, this meant that the switching frequency had to be reduced to from 9.4 to 9.0 $\mathrm{kHz}$, and the calculated value of $L_{\text {res }}$ from (5), had to be increased from $26.6 \mu \mathrm{H}$ to $37.5 \mu \mathrm{H}$ in order to maintain ZCS throughout the converter cells. The waveforms for the Lumped Retuned converter are shown in Fig. 13.

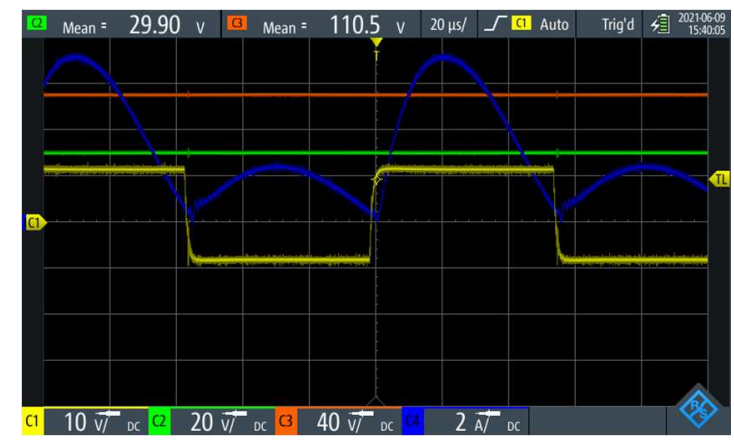

Fig. 13. Measured cell 1 input current (C4, blue, 4A/div), global gate signal (C1, yellow, 10V/div), $V_{\text {in }}(\mathrm{C} 2$, green, $20 \mathrm{~V} / \mathrm{div}), V_{\text {out }}(\mathrm{C} 3$, red, $50 \mathrm{~V} / \mathrm{div})$; time axis: $20 \mu \mathrm{s} / \mathrm{div}$

Finally, it was noted that there was excessive ringing on the turn-off voltage of $S_{3}$ for cell 1, as shown in Fig. 14(a), where an overshoot of approximately $300 \%$ is seen.

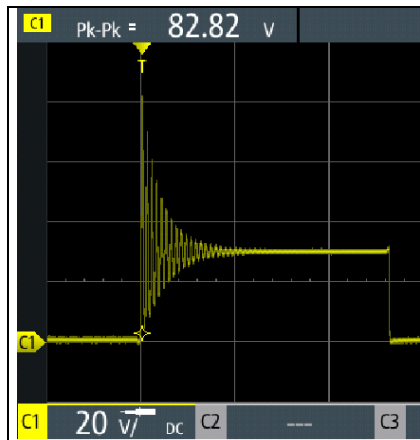

(a)

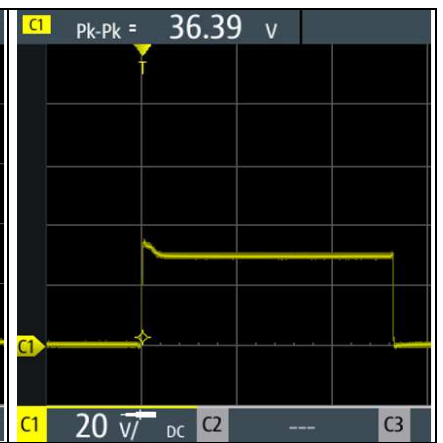

(b)
Fig. 14. Measured Cell 1, $S_{3}$ voltage (C1, yellow, 20V/div) (a) without snubber and (b) with snubber; time axis: $20 \mu \mathrm{s} / \mathrm{div}$

This was found to be due to resonance between the output parasitic capacitance of the MOSFET $S_{3}$ of cell 1 and the input inductor $L_{i n}$. A simple $400 \mathrm{nF}, 10 \Omega$ dissipative snubber was used to supress the overshoot as shown in Fig. 14(b). However, the efficiency of the prototype then dropped by $1.2 \%$ at rated power. This would be overcome in a real fullscale application using lossless clamping techniques.

\section{CONCLUSIONS}

This paper has compared a number of new, series-parallel topologies, where lumping the cell resonant inductor into a single component offers a number of advantages. Two Lumped circuits were considered; both have the significant benefit of a low-voltage interrupter switch. The use of the interrupter inductor as the resonant inductor offers further potential savings in conduction losses for the asymmetric duty-cycle converter for moderate step-up ratios. However, there are no such savings for the Retuned converter.

The impact of circuit parasitics is a particular issue with the Lumped converter as the reduced value of the resonant inductor $L_{\text {in }}$ means that parasitics then dominate the resonant frequency. Maintaining ZCS in each cell then becomes a problem. Another practical consideration is the resonance between $L_{i n}$ and the parasitic output capacitance of the cell 1, transistor $S_{3}$, which requires a relatively large snubber circuit and if dissipative, can reduce the converter efficiency.

The next stage of this work would be to carry out tests on a full-scale circuit to assess the impact of parasitics on a converter rated at several $10 \mathrm{~s} \mathrm{~kW}$ and $10 \mathrm{~s} \mathrm{kV}$ output voltage.

\section{ACKNOWLEDGEMENTS}

This work has been conducted as part of the research project 'Joint UK-India Clean Energy Centre (JUICE)' which is funded by the RCUK's Energy Programme (contract no: $\mathrm{EP} / \mathrm{P} 003605 / 1)$. The projects funders were not directly involved in the writing of this article.

\section{REFERENCES}

[1] G. Bathurst, G. Hwang and L. Tejwani, "MVDC - The New Technology for Distribution Networks," IET Conference on AC \& DC Power Transmission, 2015, pp. 1-5, doi: 10.1049/cp.2015.0037.

[2] Andreas Giannakis, Dimosthenis Peftitsis, "MVDC Distribution Grids and Potential Applications: Future Trends and Protection Challenges", Power Electronics and Applications (EPE'18 ECCE Europe) 2018 20th European Conference on, pp. P.1-P.9, 2018.

[3] Sijo Augustine, Jimmy E. Quiroz, Matthew J. Reno, and Sukumar Brahma, "DC Microgrid Protection: Review and Challenges", Sandia National Laboratories Report SAND2018-8853, 2018.

[4] H. Taghizadeh, A. M. Cross, R. Whitehouse, C. Barker, "Switched capacitor DC-DC converters for HVDC applications", IET Conference on AC \& DC Power Transmission, 10-12 Feb 2015, pp. 1-9.

[5] https://www.juice-centre.org.uk/. JUICE : Joint UK-India Clean Energy Centre, accessed 26 $6^{\text {th }}$ July 2021.

[6] J. Stewart et al., "Design and evaluation of hybrid switched capacitor converters for high voltage, high power density applications," 2018 IEEE Applied Power Electronics Conference and Exposition (APEC), 2018, pp. 105-112, doi: 10.1109/APEC.2018.8340995.

[7] R. Jevtic, M. Ylitolva and L. Koskinen, "Reconfigurable Switched Capacitor DC-DC Converter for Improved Security in IoT Devices," 2018 28th International Symposium on Power and Timing Modeling, Optimization and Simulation (PATMOS), 2018, pp. 243-247, doi: 10.1109/PATMOS.2018.8464158.

[8] N. Pallo, M. G. Taul, A. Stillwell and R. C. N. Pilawa-Podgurski, "Short-Circuit Fault Ride-Through of Flying-Capacitor Multilevel Converters through Rapid Fault Detection and Idle-mode Operation," 2020 IEEE 21st Workshop on Control and Modeling for Power Electronics (COMPEL), 2020, pp. 1-8, doi: 10.1109/COMPEL49091.2020.926574.

[9] H. Taghizadeh, A. M. Cross, R. Whitehouse and C. Barker, "An Algorithm for Automatically Calculating Component Current Ratings in Switched-Capacitor DC-DC Converters," in IEEE Access, vol. 6, pp. 15702-15712, 2018, doi: 10.1109/ACCESS.2018.2802040.

[10] H. Taghziadeh, A. M. Cross, "The effect of circuit parasitics on resonant switched capacitor converters," 2015 17th European Conference on Power Electronics and Applications (EPE'15 ECCEEurope), 2015, pp. 1-9, doi: 10.1109/EPE.2015.7309448. 